\title{
The use of creatine supplements in the military
}

\author{
Konstantinos Havenetidis
}

\section{Correspondence to}

Professor Konstantinos Havenetidis, Human Performance-Rehabilitation Laboratory, Faculty of Physical \& Cultural Education, Hellenic Army Academy, Vari-Koropiou Avenue, Vari, Attiki 16673.

Greece; khavenetidis@sse.gr

Received 22 December 2014 Revised 4 March 2015 Accepted 8 March 2015 Published Online First 29 June 2015

\section{SLinked}

- http://dx.doi.org/10.1136/ jramc-2015-000482

\section{CrossMark}

To cite: Havenetidis K. J R
Army Med Corps
2016;162:242-248.

\section{ABSTRACT}

Introduction Creatine is considered an effective nutritional ergogenic aid to enhance exercise performance. In spite of the publication of several reviews in the last decade on the topic of exercise performance/sports and creatine there is a need for an update related to the military given the lack of information in this area. The aim of this study was to critically assess original research addressing the use of creatine supplements in the military.

Methods A search of the electronic databases PubMed and SPORTDiscus, for the following key words: military personnel, trainees, recruit, soldier, physical fitness, physical conditioning, creatine supplementation, creatine ingestion, nutritional supplements to identify surveys and randomised clinical trials from journal articles and technical reports investigating the effect of creatine supplementation on military populations.

Results Thirty-three out of 90 articles examined the use of creatine as a dietary supplement in military personnel. Twenty-one studies were finally selected on the basis of stated inclusion criteria for military surveys and randomised clinical trials. Most of the surveys $(15 / 17)$ in the military indicate a high popularity of creatine (average 27\%) among supplement users. In contrast, in most of the exercise protocols used (6/9) during randomised clinical trials creatine has produced a nonsignificant performance-enhancing effect.

Conclusions Creatine is one of the most widely used supplemental compounds in the military. It is not considered a doping infraction or related to any adverse health effects but its long-term usage needs further investigation. Experimental research suggests that creatine supplementation does not enhance physical performance in the military. However, limitations in creatine dosage, military fitness testing and sample group selection might have underestimated the ergogenic properties of creatine. Recent studies also indicate positive effects on various aspects of total force fitness such as cognitive-psychomotor performance, bone health, musculoskeletal damage and neuromuscular function.

\section{INTRODUCTION}

The development of sports science has occurred alongside the development of a myriad of different ergogenic aids aimed at lowering barriers to human athletic performance. Currently, considerable attention is being devoted to the ergogenic properties of the supplement creatine. ${ }^{1}$

In the military, servicemen in a similar manner to elite athletes, also need to maximise their physical performance in order to meet the physically demanding tasks they perform. During sustained operations, many stress factors are magnified due to sleep deprivation, incomplete exercise recovery, extreme environmental conditions and calorific

\section{Key messages}

- Creatine has proven to be a popular, legal and safe supplement among military personnel, even though there is little data regarding its long-term effects.

- The limited experimental research in the military indicates a non-significant performance-enhancing effect during short-term creatine supplementation.

- Possible potentiating effects of creatine in the military may be masked if guidelines related to dosage, fitness testing and group selection are not implemented.

- Creatine can become a critical element in the success of military operations requiring rapid rehabilitation periods, high physical cognitive performance, minimal injuries and energy replenishment.

- Future researchers should evaluate creatine use during longer supplementation periods, exercise bouts simulating various military occupational tasks and more controlled experimental and field studies.

deficit. Under these circumstances servicemen may seek 'miracle' substances that will boost their performance, as failure to complete specific military events for any reason (illness or injury) would not be tolerated.

This article reviews the literature on the use of creatine supplements in the military, addressing the health and ethical issues involved, based on the hypothesis that it is an ergogenic acid which can favourably influence military exercise performance.

\section{Creatine metabolism}

Creatine is a nitrogenous organic compound found almost exclusively (98\%) in muscle and is primarily synthesised in the liver, but also in the kidneys, pancreas and mammary gland from essential (arginine, methionine) and non-essential (glycine) amino acids. $^{2}$ When formed, it is released into the bloodstream and transported to muscle tissue against a concentration gradient. The control of muscle creatine concentration is regulated by liver enzymes responsible for creatine synthesis and by creatine and creatinine (anhydro product) levels in the blood which regulate excretion rates ${ }^{3}$ (Figure 1).

Under conditions where food is unavailable, the liver can adjust its metabolism to process compounds released from muscle and other tissues in response to certain hormonal signals. An average carnivorous diet includes $1-2 \mathrm{~g}$ of creatine daily 


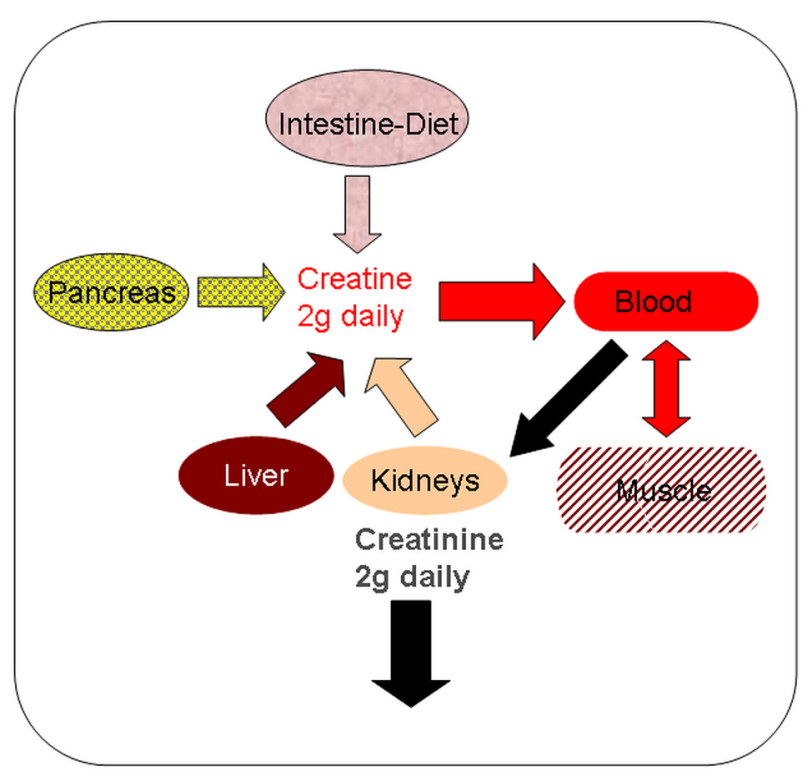

Figure 1 Creatine synthesis and excretion.

which is exclusively provided by meat products such as red and white meat, fish and molluscs; $1 \mathrm{~kg}$ of raw meat contains approximately $5 \mathrm{~g}$ of creatine. ${ }^{4}$ However, manipulation of daily creatine intake through diet seems to be a complex procedure since many factors (cooking time, type of meat, muscle site) influence creatine values after ingestion. ${ }^{5}$

The main function of creatine is to replenish creatine phosphate (CP) which is one of the limiting factors for maintaining the high rate of energy turnover during high intensity exercise. This function can be achieved during recovery periods where creatine acts as an energy transporter between the unlimited energy supplies (fat stores) and the sites where the work is produced (muscles). ${ }^{3}$ This mechanism was the theoretical background for the suggestion that exogenous creatine could improve CP resynthesis and eventually lead to performance enhancement.

\section{Exercise and creatine supplementation}

In the last 20 years substantial scientific evidence has accumulated which demonstrates the beneficial effect of creatine on exercise performance, at least under laboratory conditions where cycle ergometry, treadmill running and isokinetic-isometric dynamometry were used. ${ }^{6-8}$ Other studies conducted in more representative environments, ${ }^{9} 10$ using various sporting activities showed that performance also improved but to a significantly lower extent. This inconsistency in performance gain has been attributed to differences between studies such as exercise mode, diet, creatine dosage, number and category of participants (responders or non-responders), methods of measurements and statistical analysis.

Despite these issues there are some circumstances under which any potential benefit of creatine supplementation is magnified: a participant's body mass should show an increase of approximately $5 \%$ following the creatine loading phase, as this increase is correlated to an increase of creatine uptake in the muscle ${ }^{11}$; the recommended exercise protocol should consist of short-term (up to $30 \mathrm{~s}$ ) maximal-intensity exercise bouts performed in repeated succession ${ }^{1}$ and the recommended creatine dosage should be within the range of 20-30 g/day for a 5-7-day period (loading phase) followed by a maintenance phase of 2-5 g/day for several weeks. ${ }^{12}$ Another recommended dosing strategy (relative to body mass) involves $0.03-0.1 \mathrm{~g} / \mathrm{kg} /$ day for a 28-40-day period. ${ }^{13}$ The beverage should contain, in addition to creatine, carbohydrate and/or protein for augmenting creatine muscle retention, ${ }^{12}$ and the recommended creatine regime, totalling 20-30 g/day (loading phase), should comprise small doses (5 g) (4-6 intakes/day) of creatine monohydrate (in powder form) distributed at $2-3 \mathrm{~h}$ intervals or $1 \mathrm{~g}$ doses (20-30 intakes/day) evenly distributed at 30-min intervals. On each occasion (loading or maintenance phase) powder should be well dissolved in adequate volume of warm water (300$500 \mathrm{~mL}) .^{14} 15$

The above circumstances, in almost all cases, increase intramuscular creatine content by $10-20 \%$ alongside a $2-20 \%$ exercise performance enhancement. ${ }^{16}$ and the proposed mechanisms are listed in Table 1.

\section{METHODS}

To determine potential effects of creatine supplements on military physical performance, MEDLINE (PubMed) and SPORTDiscus were searched for original studies involving military populations (comprising only humans and aged above 19 years old) ingesting exogenous creatine. Search was performed using the terms 'military personnel', 'trainees', 'recruit' and 'soldier' with 'physical fitness', 'physical conditioning', 'creatine supplementation', 'creatine ingestion', 'nutritional supplements'. The search for relevant articles contained only the

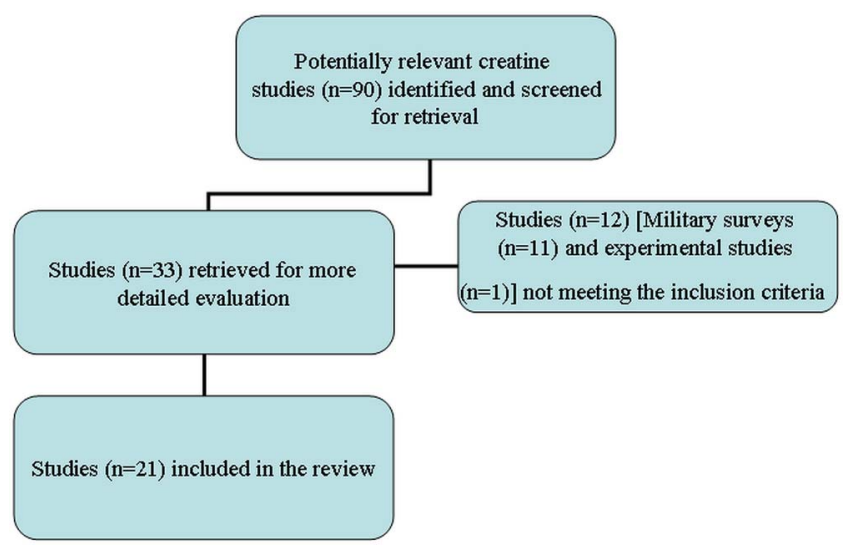

Figure 2 Study selection procedure for data synthesis.
Table 1 The mechanism of improved exercise performance from creatine supplementation

\begin{tabular}{|c|c|}
\hline $\begin{array}{l}\text { Mechanisms that facilitate exercise } \\
\text { performance }\end{array}$ & $\begin{array}{l}\text { Potentiating effects on exercise } \\
\text { performance }\end{array}$ \\
\hline $\begin{array}{l}\text { Higher initial CP availability and } \\
\text { resynthesis }\end{array}$ & $\begin{array}{l}\text { Greater dynamic strength and } \\
\text { endurance }{ }^{17}\end{array}$ \\
\hline Increased ATP resynthesis ${ }^{12}$ & $\begin{array}{l}\text { More efficient muscle damage } \\
\text { attenuation }^{18}\end{array}$ \\
\hline More efficient antioxidant activity ${ }^{19}$ & Faster and higher power production 20 \\
\hline Increased muscle protein kinetics ${ }^{21}$ & Accelerated muscle hypertrophy ${ }^{22}$ \\
\hline \multirow[t]{2}{*}{ Increased hormonal proliferation ${ }^{22}$} & $\begin{array}{l}\text { Decreased recovery time during } \\
\text { anaerobic activity }^{23}\end{array}$ \\
\hline & Enhanced fatigue resistance ${ }^{8}$ \\
\hline
\end{tabular}


Table 2 Recent surveys (1999-2014) on creatine use by military personnel

\begin{tabular}{|c|c|c|c|c|c|}
\hline \multirow[b]{2}{*}{ Study } & \multicolumn{3}{|l|}{ Subjects } & \multirow[b]{2}{*}{ Response rate $(\%)$} & \multirow[b]{2}{*}{ Usage (\%) } \\
\hline & Situation & Gender & $\mathbf{N}$ & & \\
\hline Arsenault and Kennedy ${ }^{24}$ & Army Special Forces & Men & 2215 & 99 & 18 \\
\hline McGraw et $a l^{25}$ & Army Rangers & Men & 367 & NK & 19 \\
\hline Sheppard et $a l^{26}$ & General Army & Men and women & 133 & 40 & 29 \\
\hline Deuster et $a l^{27}$ & Army Rangers & Men & 38 & 100 & 13 \\
\hline Thomasos $^{28}$ & Air Force enlisted and officers & Men and women & 10985 & NK & Rated $1 \mathrm{st}^{*}$ \\
\hline French $^{29}$ & National Guard-Reserve & Men and women & 376 & 60 & 6 \\
\hline Jaghab $^{30}$ & $\begin{array}{l}\text { Army physicians } \\
\text { Ancillary }\end{array}$ & Men and women & $\begin{array}{l}573 \\
674\end{array}$ & $\begin{array}{l}15 \\
15\end{array}$ & $\begin{array}{l}33 \\
27\end{array}$ \\
\hline Johnson et $\left.a\right|^{31}$ & Army Rangers & Men & 294 & 40 & 46 \\
\hline Lieberman et al ${ }^{\beta 2}$ & $\begin{array}{l}\text { General Army } \\
\text { Army Rangers } \\
\text { Special Forces }\end{array}$ & $\begin{array}{l}\text { Men and women } \\
\text { Men } \\
\text { Men }\end{array}$ & $\begin{array}{l}484 \\
768 \\
152\end{array}$ & $\begin{array}{l}80 \\
\text { NK } \\
\text { NK }\end{array}$ & $\begin{array}{r}5 \\
19 \\
16\end{array}$ \\
\hline Young and Stephens ${ }^{33}$ & Marines & Men & 323 & 65 & 26 \\
\hline Lieberman et $\left.a\right|^{34}$ & Active-duty Army personnel & Men and women & 990 & 80 & 42 \\
\hline Boos et $a /^{35}$ & Deployed military personnel & Men and women & 1017 & 66 & 13 \\
\hline Boos et $a l^{36}$ & Deployed servicemen & Men and women & 87 & 58 & 34 \\
\hline Casey et $a l^{37}$ & Active-duty Army personnel & Men and women & 3168 & NK & 38 \\
\hline
\end{tabular}

* Supplements ranked according to most often used; Usage, number of creatine users among supplement users.

NK, not known.

reference lists of journal articles and technical reports. All studies (military surveys and experimental studies) were initially examined. Afterwards, an additional inclusion criterion for military surveys was the citation of creatine, without any other additions (such as ephedra) in the dietary supplement lists. Different inclusion criteria were used for the experimental studies such as minimal washout periods of 28 days or more (cross-over experimental design), creatine dosage higher than $2 \mathrm{~g} /$ day for 4 days, random and concealed allocation of subjects to groups, groups of similar abilities, blinding of all subjects-supplements-test administrators. After meeting the aforementioned inclusion criteria a total number of 21 studies were included in the review (Figure 2).

\section{RESULTS}

\section{Data from military studies}

In the military, physical fitness is emphasised because of its role in military readiness and force health protection. Improving physical fitness is a vigorous and time-consuming procedure where specific exercise, nutrition and sleep guidelines need to be followed. However, current military doctrine requires the ability to maintain round-the-clock operations in order to achieve mission objectives. Under these circumstances military personnel often turn to various 'unknown' supplements in order to optimise performance in demanding situations. Table 2 demonstrates the high usage of creatine supplements among various military groups.

Most of these surveys have been conducted in the US Army, with a focus on Special Operations Forces (SOF). Several investigators 24252732 who investigated the use of dietary supplements in the US Army Rangers reported that creatine usage was high in this military subpopulation (13-19\%), while, others ${ }^{31} 33$ reported even higher usage (26\% and 46\%) using participants from various groups of SOF (Marines, Rangers). Among the six categories used in that survey, ${ }^{31}$ (anabolic steroids, amino acids, thermogenics, androstenedione, creatine, protein) creatine supplements were the second most commonly used dietary supplement. In these studies, creatine supplements were consumed by SOF at rates similar to athletic populations possibly because SOF are also intrinsically motivated to maximise their performance. Similar results were also presented by investigators, ${ }^{26283034}$ who used large-scale surveys and assessed various

Table 3 Experimental studies investigating the effect of creatine supplementation on military personnel's exercise performance

\begin{tabular}{llllll}
\hline Study (design) & Subjects & & & \\
\cline { 2 - 3 } & Personnel & N & Dose and duration of creatine used & Exercise method
\end{tabular}


non-SOF populations (Army physicians, Administrative Officers-Technicians, Air Force enlisted and officers, active-duty Army personnel). In these surveys creatine was administrated by a high proportion of military personnel (27-33\%) and on a regular basis compared with other supplements.

By contrast, other studies ${ }^{29}{ }^{32}$ have shown that creatine use was not popular (5-6\%) among general Army personnel and military National Guard-Reserve participants with Vitamin C and calcium being the most common dietary supplements used (13\%).

Apart from US troops, Boos et al, ${ }^{35}$ in a large observational study of 1017 deployed British servicemen to Iraq reported that $13 \%$ of the users preferred creatine among other nutritional supplements. The same investigators ${ }^{36}$ highlighted the issue and potential concerns regarding the unregulated use of dietary supplements within the British military in Afghanistan; again one of the main types of supplements used by that sample group $(n=87)$ was creatine $(34 \%)$ surpassed only by protein. Casey et $a l,{ }^{37}$ in a survey comprising various British Army troops (Infantry, Parachute Regiment Units, Royal Armoured Corps, Royal Artillery and Royal Engineers) also reported that creatine was widely consumed (38\%) among supplement users.

In one of the surveys conducted, ${ }^{26}$ creatine users extended the supplementation period (from 4 weeks to 40 weeks) resulting in a 5-10-fold increase in the total recommended creatine ingested. Most of the users relied on popular media such as fitness magazines, rather than nutritionists for information on creatine, suggesting that creatine users, in their pursuit of a performance advantage often follow creatine regimens of questionable efficacy and/or safety. Experimental research in the military about the use of specific supplements is limited, and especially so for creatine ingestion (Table 3 ).

In a study, ${ }^{38}$ conducted in the USA, the role of creatine supplements was assessed in a group of 24 Navy Seals. The researchers measured a series of physiological parameters such as volume of intracellular-extracellular fluid and body fat percentage as well as physical performance (obstacle course passing time). The results showed that the creatine group presented significantly higher intracellular fluid volume but not extracellular or total water volume. Warber et al, ${ }^{40}$ tested 13 male soldiers performing three consecutive military obstacle course runs followed by a rifle marksmanship task on three occasions each separated by 5 days. The same soldiers also completed a controlled strength test which comprised repeated bench presses (five sets to failure at $70 \%$ of one repetition maximum) and answered the Profile of Mood States questionnaire during each test session. Creatine usage ( $24 \mathrm{~g} /$ day for 5 days) significantly improved performance during the controlled strength test by $14 \%$ but did not significantly improve military obstacle course performance, marksmanship or mood.

By contrast, Baker-Fulco et $a l,{ }^{41}$ showed no improvement in exercise performance following creatine ingestion. The authors examined whether creatine supplementation improves muscle performance in a group of seven Army recruits during exposure to acute hypobaric hypoxia. The exercise involved submaximal intermittent static knee contractions interspersed with maximal voluntary contractions every minute to exhaustion after supplementation with creatine. There was no effect of creatine on maximal force, muscle endurance, or recovery in normoxia or hypobaric hypoxia but the small number of participants may have affected the statistical analysis. Koenig et al, ${ }^{43}$ investigated the effect of creatine supplements $(25 \mathrm{~g} /$ day for 5 days $)$ on repeated static jump performance (two sets of 10 jumps in $60 \mathrm{~s}$ ) using a group of Army recruits $(n=10)$. The authors demonstrated that creatine supplementation significantly influenced jump height after the sixth bout $(\mathrm{p}<0.05)$ and prevented the increasing pattern of fatigue that occurs in repeated jump performance.

Despite the fact that almost all studies demonstrated no beneficial effect of creatine on military exercise performance, further scientific data are required before the military community is fully apprised of the effects of creatine administration. Overcoming previous limitations of small sample group and poor study design, recent studies using non-military groups have confirmed the beneficial effect caused by creatine supplementation on maximal muscle strength-endurance, anaerobic power and speed endurance ${ }^{44-47}$ using various exercise modes. These studies could be used as a reference for the 'athlete' in uniform as maximal strength and power are increasingly being recognised as potentially important components of military fitness. ${ }^{48}$

However, optimising dosage selection is essential in order to ensure the effectiveness of creatine loading. The amount, form and frequency of creatine ingested should be examined as well as the rate of creatine uptake (via biopsies or excretion in urine) in order to determine the daily creatine gain. If these invasive measurements are not feasible in military populations then a simple monitoring of body weight increase $(2-5 \%)$ within the first 2-4 days of loading would be an adequate indication of efficient creatine uptake in the muscle. This was mentioned as a limitation in military studies, ${ }^{38} 40$ where no significant differences existed in obstacle course performance following creatine supplementation. Another possible explanation for the negative results in that study ${ }^{40}$ was probably the use of creatine supplements in the form of sports bars which was not evaluated as thoroughly in relation to creatine uptake in the muscle as other forms such as creatine monohydrate. ${ }^{1}$

The selection of the military sample group is another issue that might influence the response to creatine supplementation. The recruits in the study of Ensign et $a l,{ }^{38}$ were SOF units who demonstrated smaller insignificant improvement in their performances while, general military populations 4043 showed significant performance potentiation especially in strength abilities. This may be explained by the elite group's (Navy SEALs) intense daily physical training giving elevated creatine levels in the muscle which limits any further increase in intramuscular creatine levels and consequently improvement in exercise performance, which is supported by evidence from elite athletes from various sports who follow intense training where creatine supplementation does not significantly improve exercise performance. ${ }^{9} 10$

It is noteworthy that in aerobic sports, energy is predominately provided by aerobic degradation of carbohydrates (glycolysis) and fat oxidation. ${ }^{49}$ These procedures provide low and constant energy supply but they do not relate to creatine metabolism. Alternatively, in power sports energy is predominately provided by phosphates (CP, ATP) which are limited, but characterised by high rates of energy supply. ${ }^{50}$ On this occasion, maintaining high phosphagen levels is heavily dependent on creatine availability which rapidly replenishes $\mathrm{CP}$ and consequently ensures the continuation of maximal-intensity exercise. Additionally, during rest periods on an interval-type exercise, creatine serves as an intramuscular high-energy phosphate shuttle between the mitochondria (site of ATP production) and myosin cross-bridge sites that initiate muscular contraction (site of ATP utilisation). ${ }^{51}$ In that sense, during the most intense and short periods of exercise, the muscle will tax the creatine stores most highly, ${ }^{52}$ leading to a potentiating effect, following exogenous creatine loading, mainly in short-duration sports involving repeated and sudden bursts of movement (sprints, jumps). 
This suggests that the selection of the exercise protocol for evaluating creatine effects on military performance is highly relevant. The obstacle course timings showed insignificant and/ or small improvements in the creatine group, ${ }^{38} 40$ possibly because it is dependent on energy sources from anaerobic and aerobic pathways which are less creatine-dependent. Similarly, the use of continuous, submaximal activity $(5 \mathrm{~km}$ run and $10 \mathrm{~km}$ march) in the study of Bennet et al, ${ }^{39}$ possibly excluded the facilitation of exogenous creatine on energy supply during initiation and/or rest periods due to the predominance of other energy pathways. Marksmanship which was also used as a performance measure in the study of Warber et $a l,{ }^{40}$ was not affected by creatine supplementation, presumably due to the technical rather than the metabolic demands that characterise this military task. Hence, failure to relate the military occupational tasks as well as the appropriate fitness test used with the energetics of creatine metabolism, may limit the validity of the conclusions of these experiments. ${ }^{88-43}$

Additionally, it is preferable not to use the 'traditional' military fitness tests ( 2 min push-ups, 1 min sit-ups, pull-ups, 2 min curl-ups) since they are not representative indicators of performance of typical, loaded military tasks. Furthermore they impose a systematic bias against larger participants. ${ }^{53}$ A possibly successful schema would be the use of militarily relevant tests consisting of strength/sprint exercise type such as a timed $400 \mathrm{~m}$ run with an $18 \mathrm{~kg}$ load, a timed simulated casualty rescue with the fighting load, a repetitive lift and carry, single lift of a weighted ammunition box, a carry task, a fire-manoeuvre sequence and a trench dig. ${ }^{5455}$ These tests have been shown to be reliable, ${ }^{54}$ and valid as they simulate common battlefield activities where soldiers sprint to cover and move their body mass and transport wounded soldiers, weapons and/or supplies requiring absolute strength, speed and power.

There is a growing number of studies, ${ }^{18} 20215657$ which indicate positive effects of creatine supplementation on exercise performance and on several aspects of the health and wellness spectrum. This spectrum currently represents the new approach to fitness in the military called 'total force fitness' which seamlessly combines multiple components of fitness in the mind and the body. ${ }^{58}$ It seems that potentially, several fitness components besides the physical (strength, muscle endurance, speed, power, agility) can be facilitated by creatine supplementation. These include nutritional, medical and psychological components.

One of the goals of nutritional fitness is to establish and meet specific nutritional requirements, a procedure which varies between individuals as in the case of vegetarians, who exclude meat products and consequently creatine from the diet. Since many military missions demand high speed and explosive power, which rely on $\mathrm{CP}$ availability, creatine supplementation will provide an alternative method to increase CP stores and consequently maximise nutritional fitness without altering personal dietary habits. It has been reported that individuals with a lower initial level of total muscle creatine content possess higher potential to improve performance in response to creatine supplementation. ${ }^{1}$ Medical fitness refers to an injury-free, optimal and healthy status where the warfighter is characterised by the highest physiological and psychological readiness. ${ }^{59}$ Studies ${ }^{18} 21$ indicate that creatine supplementation can be an effective strategy for maximising medical fitness by attenuating the loss in muscle-mass-strength during immobilisation, acting as an effective antioxidant agent after more intense resistance training sessions, ${ }^{1}$ and improving the force-velocity relationship as well as mean muscle fibre conduction velocity during voluntary and electrically induced contractions. ${ }^{20}$ These beneficial actions can play a crucial role during short rehabilitation periods in ensuring rapid deployment and/or during long-lasting treatment after serious injuries (blast injuries, bone fractures) and in achieving a full restoration of skeletal and neuromuscular function. Psychological fitness is defined as the integration and optimisation of mental, emotional, and behavioural abilities and capacities in order to optimise performance and strengthen the resilience of warfighters. ${ }^{60}$ It seems that creatine supplementation can positively influence many aspects of psychological fitness such as awareness, coping, decision making, resilience, burn-out and engagement which are hindered by sleep deprivation and impair the soldiers' capacity to successfully fulfil their missions. Two studies ${ }^{56} 57$ demonstrated that the creatinesupplemented group presented a substantial resistance to cognitive and psychomotor performance deterioration (choice reaction time, balance, number of errors) as well as in mood swings in individuals suffering from 24-h sleep deprivation. However, there is still a need for targeted research with greater representation among military groups and the use of a plethora of military occupational tasks in order to quantify any potential benefits of creatine and minimise any clinical risks.

\section{Health and ethical issues}

Most anecdotal reports of side effects have described an increased incidence of dehydration or muscle cramping or gastrointestinal distress, ${ }^{6162}$ especially in athletes who exercise in hot and humid environments. These potential side effects were based on athletic media reports in the late 1990s, were never supported by clinical evidence and the athletes did not report a consistent pattern of 'perceived' negative side effects as a result of the creatine-supplementation protocol. ${ }^{63} \mathrm{~A}$ recent meta-analysis found no evidence to support the concept that creatine supplementation either hinders the body's ability to dissipate heat or negatively affects the athlete's body fluid balance. ${ }^{64}$ In fact, in most of the studies it was demonstrated that creatine ingestion may actually have promoted hydration, and reduce thermal stress during exercise in the heat. ${ }^{116365-68}$

Other studies have also demonstrated that creatine ingestion has no negative effects on renal, hepatic, cardiac or muscle function. ${ }^{69-72}$ Furthermore, the incidence of human adverse reactions is limited and not necessarily linked to creatine itself, but rather to violation of the creatine supplementation protocols for potentially greater enhancement. ${ }^{69}$ However, one of the greatest concerns about creatine use is that few authors have examined its long-term effects on users' health. Kim et al ${ }^{73}$ suggested that exogenous creatine in quantities greater than $3-5 \mathrm{~g} /$ day is considered to apply a heavy load on kidney function and should not be used by individuals with pre-existing renal disease or those with a potential risk of renal dysfunction such as diabetes, hypertension or reduced glomerular filtration rate. Considering that in the loading phase a typical creatine regime includes 20 $25 \mathrm{~g} /$ day, this high quantity combined with a long supplementation period can potentially cause a cumulative detrimental effect on users' renal health. Additionally, military groups such as SOF units operating under hot and humid conditions for long periods while carrying heavy loads ${ }^{74}$ may magnify potential adverse health effects of creatine which are considered negligible in athletes who participate in controllable short-term exercise trials.

The evidence supports the advice that creatine users should not: become hypohydrated during exercise, ${ }^{15}{ }^{75}$ with reductions in water intake less than 1.5-2 L/day, ingest creatine doses more than $20-25 \mathrm{~g} /$ day and $5-7 \mathrm{~g} /$ day for the loading and maintenance phase, respectively, ${ }^{76}$ extend the supplementation period 
longer than 7 days and 120 days for the loading and maintenance phases, respectively, ${ }^{77}$ and follow strenuous exercise protocols under hot environmental conditions for extended time periods, since no authors have examined the long-term effects of creatine on thermoregulation. ${ }^{64}$ Considering that the mechanisms of creatine action are incompletely understood and therefore, the long-term clinical safety cannot be guaranteed, these guidelines may serve as a means of health prevention measures. Furthermore, annual training plans need to be designed by military professionals which will embody scientific methodology by the use of periodisation models, acclimatisation techniques and nutritional support in order to avoid health problems in military servicemen caused by intense training and not by creatine per se. There is also concern about the synergistic or antagonistic role of creatine in relation to other supplements such as caffeine, ${ }^{78}$ vitamins, ${ }^{79}$ as well as the potential risks that might emerge from its frequent mixture with unknown substances. ${ }^{80}$ These phenomena underscore the conduction of recent surveys by the military management where the efficacy and safety of various forms of creatine will be assessed based on its interaction with other supplements/pharmaceuticals.

In relation to the ethical aspect of creatine supplementation on military populations, it must be noted that currently it does not appear on the International Olympic Committee's list of banned substances, while some ergogenic aids are banned by sporting governing bodies due to their detrimental effects on athletes' health, while others are deemed to confer what is seen to be an unfair advantage. These considerations might raise the ethical question as to whether the use of creatine should be banned above specific concentration levels, based on its ergogenic effect akin to the former ban on caffeine which is a normal dietary component. Such a prohibition would be difficult to enforce due to the difficulties in detecting creatine turnover because it is produced naturally by the body and is part of any normal meat-containing diet; even with the use of repeated muscle biopsies (which is not feasible in military populations) this prohibition might end up punishing servicemen who are at the top of the biological range in terms of muscle creatine levels.

\section{CONCLUSIONS}

Although research on creatine involved early experimental contributions on such diverse topics as high-energy compounds, urinary constituents and diagnosis of myocardial infarctions, this simple compound has not yet, after 150 years, yielded all its secrets. Despite the relatively short time of investigation considerable published research indicates that creatine ingestion is a new ergogenic aid to enhance exercise performance. This review has provided some insight into the use of creatine supplements by military personnel, the effects on military exercise performance, the methodology involved in the few experimental studies performed and how this methodology affected the participants' abilities under baseline/placebo and creatine conditions. A series of military surveys have clearly shown that creatine has rapidly become one of the most popular, legal and safe supplements among military personnel, even though there is little data, regarding its long-term effects.

The limited experimental research also suggests that shortterm creatine supplementation is not related to a significantly enhanced physical performance in the military. It seems that possible potentiating effects in the military may be masked if specific guidelines are not followed in terms of creatine dosage, military fitness testing and sample group selection. Under these circumstances, the possibility that creatine supplementation may enhance military exercise performance should be investigated further, in order to allow data to be applicable and compatible with the new holistic doctrine for military fitness.

Competing interests None declared.

Provenance and peer review Not commissioned; externally peer reviewed.

\section{REFERENCES}

1 Cooper R, Naclerio F, Allgrove J, et al. Creatine supplementation with specific view to exercise/sports performance: an update. J Int Soc Sports Nutr 2012;9:33.

2 Brosnan JT, da Silva RP, Brosnan ME. The metabolic burden of creatine synthesis. Amino Acids 2011:40:1325-31.

3 Longo N, Ardon O, Vanzo R, et al. Disorders of creatine transport and metabolism. Am J Med Genet C Semin Med Genet 2011;157C:72-8.

4 Reig M, Aristoy MC, Toldrá F. Variability in the contents of pork meat nutrients and how it may affect food composition databases. Food Chem 2013;140:478-82.

5 Jayasena DD, Jung S, Bae YS, et al. Changes in endogenous bioactive compounds of Korean native chicken meat at different ages and during cooking. Poult Sci 2014;93:1842-9.

6 Havenetidis K, Cooke CB, Butterly R, et al. Incorrect calculation of power outputs masks the ergogenic capacity of creatine supplementation. Appl Physiol Nutr Metabol 2006:31:635-42.

7 Fukuda $\mathrm{DH}$, Smith $\mathrm{AE}$, Kendall $\mathrm{KL}$, et al. The effects of creatine loading and gender on anaerobic running capacity. J Strength Cond Res 2010;24:1826-33.

8 Johnston APW, Burke DG, MacNeil LG, et al. Effect of creatine supplementation during cast-induced immobilization on the preservation of muscle mass, strength, and endurance. J Strength Cond Res 2009;23:116-20.

9 Claudino JG, Mezêncio B, Amaral S, et al. Creatine monohydrate supplementation on lower-limb muscle power in Brazilian elite soccer players. J Int Soc Sports Nutr 2014;18:11-32

10 Lamontagne-Lacasse M, Nadon R, Goulet EDB. Effect of creatine supplementation on jumping performance in elite volleyball players. Int I Sports Physiol Perform 2011:6:525-33.

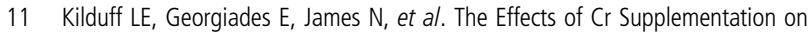
cardiovascular, metabolic, and thermoregulatory responses during exercise in the heat in endurance-trained humans. Int J Sport Nutr Exerc Metab 2004;14:443-60.

12 Buford T, Kreider R, Stout J, et al. International Society of Sports Nutrition position stand: creatine supplementation and exercise. J Int Soc Sports Nutr 2007:4:6.

13 Hickner R, Dyck D, Sklar J, et al. Effect of 28 days of creatine ingestion on muscle metabolism and performance of a simulated cycling road race. J Int Soc Sports Nutr 2010;7:26.

14 Deldicque L, Décombaz J, Zbinden Foncea $\mathrm{H}$, et al. Kinetics of creatine ingested as a food ingredient. Eur J App/ Physiol 2008;102:133-43.

15 Sale C, Harris RC, Florance J, et al. Urinary creatine and methylamine excretion following $4 \times 5 \mathrm{~g} \times$ day $^{-1}$ or $20 \times 1 \mathrm{~g} \times$ day $^{-1}$ of creatine monohydrate for 5 days. J Sports Sci 2009;27:759-66.

16 Havenetidis K. Assessment of the ergogenic properties of creatine using an intermittent exercise protocol. J Exerc Physiol 2005;8:26-33.

17 Cribb PJ, Williams $A D$, Hayes $A$. A creatine protein-carbohydrate supplement enhances responses to resistance training. Med Sci Sports Exerc 2007;39:1960-8.

18 Bassit RA, Pinheiro $\mathrm{CH}$, Vitzel $\mathrm{KF}$, et al. Effect of short-term creatine supplementation on markers of skeletal muscle damage after strenuous contractile activity. Eur J Appl Physiol 2010;108:945-55.

19 Sestili P, Martinelli C, Bravi G, et al. Creatine supplementation affords cytoprotection in oxidatively injured cultured mammalian cells via direct antioxidant activity. Free Radic Biol Med 2006;40:837-49.

20 Bazzucchi I, Felici F, Sacchetti M. Effect of short-term creatine supplementation on neuromuscular function. Med Sci Sports Exerc 2009:41:1934-41.

21 Candow DG, Little JP, Chilibeck PD, et al. Low-dose creatine combined with protein during resistance training in older men. Med Sci Sports Exerc 2008;40:1645-52.

22 Burke DG, Candow DG, Chilibeck PD, et al. Effect of creatine supplementation and resistance-exercise training on muscle insulin-like growth factor in young adults. Int J Sport Nutr Exerc Metab 2008;8:389-98.

23 Camic CL, Hendrix CR, Housh TJ, et al. The effects of polyethylene glycosylated creatine supplementation on muscular strength and power. I Strength Cond Res 2010;24:3343-51.

24 Arsenault J, Kennedy J. Dietary supplement use in U.S. Army Special Operations candidates. Mil Med 1999;164:495-501.

25 McGraw SM, Tharion WJ, Lieberman HR. Use of nutritional supplements by U.S Army Rangers. FASEB J 2000;14:A742.

26 Sheppard HL, Raichada SM, Kouri KM, et al. Use of creatine and other supplements by members of civilian and military health clubs: a cross-sectional survey. Int I Sport Nutr Exerc Metab 2000;10:245-59.

27 Deuster PA, Sridhar A, Becker WJ, et al. Health assessment of U.S. Army Rangers. Mil Med 2003;168:57-62. 
28 Thomasos C. Assessment of Air Force dietary supplement usage by major commands. Presented at the Institute of Medicine Workshop on Dietary Supplement Use by Military Personnel; Washington DC. 13 February 2007.

29 French S. Insights into dietary supplement usage by U.S. active military personnel. Presented at the Institute of Medicine Workshop on Dietary Supplement Use by Military Personnel; Washington DC. 13 February 2007.

30 Jaghab D. Survey of Army health care providers concerning dietary supplements. Presented at the Institute of Medicine Workshop on Dietary Supplement Use by Military Personnel 2007; Washington DC. 13 February 2007.

31 Johnson AE, Haley CA, Ward JA. Hazards of dietary supplement use. J Spec Oper Med 2007;7:30-8

32 Lieberman HR, Stavinoha T, McGraw S, et al. Use of dietary supplements in U.S. Army populations. Presented at the Institute of Medicine Workshop on Dietary Supplement Use by Military Personnel 2007; Washington, DC. 13 February 2007.

33 Young CR, Stephens MB. Sports and nutritional supplement use in USMC recruits: a pilot study. Mil Med 2009;174:158-61.

34 Lieberman HR, Stavinoha TB, McGraw SM, et al. Use of dietary supplements among active-duty US Army soldiers. Am J Clin Nutr 2010;92:985-95.

35 Boos CJ, Wheble GA, Campbell MJ, et al. Self-administration of exercise and dietary supplements in deployed British military personnel during Operation TELIC 13. J R Army Med Corps 2010;156:32-6.

36 Boos CJ, Simms P, Morris FR, et al. The use of exercise and dietary supplements among British soldiers in Afghanistan. J R Army Med Corps 2011;157:229-32.

37 Casey A, Hughes J, Izard RM, et al. Supplement use by UK-based British Army soldiers in training. Br J Nutr 2014;112:1175-84.

38 Ensign WY, Jacobs I, Prusaczyk WK, et al. Effects of creatine supplementation on short-term exercise performance of U.S. Navy Seals. Technical Report No. 99-1. San Diego, CA: Naval Health Research Center, 1999.

39 Bennett T, Bathalon G, Armstrong D, et al. Effect of creatine on performance of militarily relevant tasks and soldier health. Mil Med 2001;166:996-1002.

40 Warber JP, Tharion WJ, Patton JF, et al. The effect of creatine monohydrate supplementation on obstacle course and multiple bench press performance. J Strength Cond Res 2002;16:500-8.

41 Baker-Fulco CJ, Fulco CS, Kellogg MD, et al. Voluntary muscle function after creatine supplementation in acute hypobaric hypoxia. Med Sci Sports Exerc 2006;38:1418-24.

42 Armentano MJ, Brenner AK, Hedman TL, et al. The effect and safety of short-term creatine supplementation on performance of push-ups. Mil Med 2007;172:312-17.

43 Koenig CA, Benardot D, Cody M, et al. Comparison of creatine monohydrate and carbohydrate supplementation on repeated jump height performance. J Strength Cond Res 2008:22:1081-6.

44 Law YL, Ong WS, GillianYap TL, et al. Effects of two and five days of creatine loading on muscular strength and anaerobic power in trained athletes. J Strength Cond Res 2009:23:906-14.

45 Percário S, Domingues SP, Teixeira LF, et al. Effects of creatine supplementation on oxidative stress profile of athletes. J Int Soc Sports Nutr 2012:9:56. http://www. biomedcentral.com/content/pdf/1550-2783-9-56.pdf (accessed 10 Feb 2015).

46 Deminice R, Rosa FT, Franco GS, et al. Effects of creatine supplementation on oxidative stress and inflammatory markers after repeated-sprint exercise in humans. Nutrition 2013;29:1127-32.

47 Camic CL, Housh TJ, Zuniga JM, et al. The effects of polyethylene glycosylated creatine supplementation on anaerobic performance measures and body composition. J Strength Cond Res 2014;28:825-33.

48 Department of the Army. U.S. Army Training and Doctrine Command: Army Physical Readiness Training Circular. Technical Report No. 3-22.20. Washington DC: Headquarters, 2010.

49 McArdle WD, Katch Fl, Katch VL. Introduction to energy transfer. In: Darcy P, ed. Exercise physiology: energy, nutrition and human performance. 5th edn. Philadelphia, PA: Lippincott, Williams, and Wilkins, 2001:115-73.

50 Williams MH, Branch JD. Creatine supplementation and exercise performance: an update. J Am Coll Nutr 1998;17:216-34.

51 Wallimann T, Wyss M, Brdiczka D, et al. Intracellular compartmentation, structure and function of creatine kinase isoenzymes in tissues with high and fluctuating energy demands: the 'phosphocreatine circuit' for cellular energy homeostasis. Biochem J 1992;281:21-40.

52 Wyss M, Kaddurah-Daouk R. Creatine and creatinine metabolism. Physiol Rev 2000;80:1107-213
53 Vanderburgh PM. Occupational relevance and body mass bias in military physical fitness tests. Med Sci Sports Exerc 2008:40:1538-45.

54 Harman EA, Gutekunst DJ, Frykman PN. Effects of two different eight-week training programs on military physical performance. J Strength Cond Res 2008;22:524-34.

55 Richmond VL, Rayson MP, Wilkinson DM, et al. Development of an operational fitness test for the Royal Air Force. Ergonomics 2008;51:935-46.

56 Rawson ES, Venezia AC. Use of creatine in the elderly and evidence for effects on cognitive function in young and old. Amino Acids 2011;40:1349-62.

57 McMorris T, Harris RC, Swain J, et al. Effect of creatine supplementation and sleep deprivation, with mild exercise, on cognitive and psychomotor performance, mood state, and plasma concentrations of catecholamines and cortisol. Psychopharmacology 2006;185:93-103.

58 Jonas WB, O'Connor FG, Deuster $\mathrm{P}$, et al. Why total force fitness? Mil Med 2010;175:6-13

59 O'Connor FG, Deuster PA, DeGroot DW, et al. Medical and environmental fitness. Mil Med 2010;175:57-64.

60 Bates MJ, Bowles S, Hammermeister J, et al. Psychological Fitness. Mil Med 2010;175:21-38

61 Terjung RL, Clarkson P, Eichner ER, et al. American College of Sports Medicine roundtable: the physiological and health effects of oral creatine supplementation. Med Sci Sports Exerc 2000;32:706-17

62 Bailes JE, Cantu RC, Day AL. The neurosurgeon in sport: awareness of the risks of heatstroke and dietary supplements. Neurosurg Online 2002;51:283-8.

63 Greenwood M, Kreider RB, Greenwood L, et al. Cramping and injury incidence in collegiate football players are reduced by creatine supplementation. J Ath/ Train 2003;38:216-19.

64 Lopez RM, Casa DJ, McDermott BP, et al. Does creatine supplementation hinder exercise heat tolerance or hydration status? A systematic review with meta-analyses. J Ath/ Train 2009;44:215-23.

65 Greenwood M, Kreider RB, Melton C, et al. A. Creatine supplementation during college football training does not increase the incidence of cramping or injury. $\mathrm{Mol}$ Cell Biochem 2003:244:83-8.

66 Easton C, Turner S, Pitsiladis YP. Creatine and glycerol hyperhydration in trained subjects before exercise in the heat. Int I Sport Nutr Exerc Metab 2007;17:70-91.

67 Kern M, Podewils LJ, Vukovich $\mathrm{M}$, et al. Physiological response to exercise in the heat following creatine supplementation. J Exerc Physiol 2001;4:18-27.

68 Mendel RW, Blegen M, Cheatham C, et al. Effects of creatine on thermoregulatory responses while exercising in the heat. Nutrition 2005;21:301-7.

69 Thorsteinsdottir B, Grande J, Garovic V. Acute renal failure in a young weight lifter taking multiple food supplements, including creatine monohydrate. J Ren Nutr 2006;16:341-5.

70 Tarnopolsky M, Zimmer A, Paikin J, et al. Creatine monohydrate and conjugated linoleic acid improve strength and body composition following resistance exercise in older adults. PLOS ONE. Published Online First: 3 October 2007. http://journals.plos. org/plosone/article?id=10.1371/journal.pone.0000991 (accessed 10 Feb 2015).

71 Dalbo V, Roberts M, Stout J, et al. Putting to rest the myth of creatine supplementation leading to muscle cramps and dehydration. Br J Sports Med 2008:42:567-73

72 Rawson ES. Safety of creatine supplementation. Subcell Biochem 2007;46:275-89.

$73 \mathrm{Kim} \mathrm{HJ}, \mathrm{Kim}$ CK, Carpentier A, et al. Studies on the safety of creatine supplementation. Amino Acids 2011;40:1409-18.

74 Sporiš $G$, Harasin D, Bok D, et al. Effects of a training program for special operations battalion on soldiers' fitness characteristics. J Strength Cond Res 2012;26:2872-82.

75 Poortmans JR, Francaux M. Creatine consumption and health. In: Stout JR, Antonio J, Kalman D, eds. Essentials of creatine in sports and health. Totowa, NJ: Humana Press, 2008:127-72.

76 Shao A, Hathcock J. Risk assessment for creatine monohydrate. Regul Toxicol Pharmacol 2006; 45:242-51.

77 Tarnopolsky MA. Caffeine and creatine use in sport. Ann Nutr Metab 2010;57:1-8.

78 Hespel P, Op't Eijnde B, Van M. Opposite actions of caffeine and creatine on muscle relaxation time in humans. J App/ Physiol 2002;92:513-18.

79 Korzun WJ. Oral creatine supplements lower plasma homocysteine concentrations in humans. Clin Lab Sci 2004;17:102-6.

80 Greenwood MRC, Oria M. Other dietary supplements in military personnel. In: Greenwood MRC, Oria M, eds. Use of dietary supplements by military personnel. Washington DC: Institute of Medicine of the National Academies, 2008:84-295. 